\title{
EM Defesa do Uso da Pesquisa-AÇão na Pesquisa EM ADMINISTRAÇÃo NO BRASIL
}

\section{In DEFENSE of ACTION RESEARCH AdOPTION IN MANAGEMENT RESEARCH, IN BRAZIL}

JONATHAN FREITAS (jonathanbra@gmail.com)

DANiEl CALBino

AleXANDRE SANTOS

RAFAel Diogo Pereira

UniversidAde FedERAL DE Minas Gerais

\section{RESUMO}

Uma análise realizada com base nos trabalhos publicados em eventos nacionais de Administração revela que a Pesquisa-Ação tem sido utilizada, no Brasil, de maneira consideravelmente restrita. Aparentemente, esse fato se deve à dificuldade, por parte dos pesquisadores, de justificarem o mérito acadêmico dessa estratégia metodológica frente à abordagem científica tradicional. Diante disso, supõe-se que uma apropriada compreensão da natureza da Pesquisa-Ação e dos pressupostos que a fundamentam poderia contribuir para sustentar uma argumentação a favor da adequação dessa estratégia. Nesse sentido, o objetivo do trabalho foi recuperar as principais características da Pesquisa-Ação explicitando os traços distintivos que lhe conferem uma identidade particular, legítima e relevante no âmbito da pesquisa científica. Concluiu-se que a Pesquisa-Ação é usualmente adotada quando a problemática pesquisada mostra-se complexa e pouco explorada, demandando uma forte interação dos pesquisadores com o objeto de pesquisa e partindo-se de questões que sejam prioritariamente relevantes para os próprios sujeitos imersos na situação sob estudo. Assim, pode ser considerada uma estratégia de engajamento consideravelmente relevante para as ciências organizacionais em geral, e para as administrativas, em particular.

Palavras-chave: Pesquisa-Ação; estratégia; administração. 


\section{ABSTRACT}

An analysis of the work published at national Management events shows that action research in Brazil has been used in a considerably restricted manner. It seems the reason for this is the difficulty faced by researchers in justifying the academic merits of this methodological strategy versus the traditional scientific approach. Thus, a proper understanding of the nature of action research and its supportive assumptions could help to sustain the argument in favor of its adoption. Accordingly, the objective of the work is to revisit the main characteristics of action research, highlighting the distinctive features that grant it a unique identity: one that is legitimate and relevant in the context of scientific research. It is concluded that action research is normally adopted when the issue researched is shown to be complex and less studied, thus requiring significant interaction between the researchers and research object, being based on questions that are of main importance to the actual subjects involved. It can, therefore, be considered an approach that is of definite relevance to organizational science in general and management ones in particular.

Keywords: Action Research; strategy; management.

\section{INTRoduÇão: A Pesquisa-AÇÃo na Pesquisa em AdMinistração No BRASIL: UMA LACUNA METODOLÓGICA}

A Pesquisa-Ação (PA) mostra-se consolidada em vários países da Europa e nos Estados Unidos da América (EUA), estando relacionada principalmente a parcerias entre o setor industrial e universidades para o desenvolvimento de pesquisas de interesse comum (COGHLAN, 2004). Contudo, ao fazermos um levantamento do uso da Pesquisa-Ação em trabalhos publicados em encontros acadêmicos brasileiros da área de Administração, constatamos um quadro antagônico ao apresentado no exterior.

Com base no site da Associação Nacional de Pós-Graduação e Pesquisa em Administração (ANPAD), foi realizada uma busca do termo pesquisa-ação (e de expressões correlatas) nos artigos publicados nas seguintes edições de eventos com repercussão nacional - Encontro de Ensino e Pesquisa em Administração e Contabilidade, EnEPQ (2007); Encontro Nacional dos Programas de Pós-Graduação em Administração, 
EnANPAD (1997 a 2008); Encontro de Marketing da Anpad, EMA (2004, 2006, 2008); Encontro de Estudos em Estratégia, 3Es (2003, 2005, 2007); Encontro de Estudos Organizacionais, EnEO (2000, 2002, 2004, 2006, 2008); Simpósio (2006, 2008); Encontro de Administração Pública e Governança, EnPGR (2004, 2006, 2008); Encontro de Gestão de Pessoas e Relações de Trabalho, EnGPR (2007); e Encontro de Administração da Informação, EnADI (2007) - foram identificados 68 trabalhos que faziam menção a essa temática. Contudo, apenas 11 utilizaram efetivamente a Pesquisa-Ação como estratégia de pesquisa dos quais dez foram apresentados no EnANPAD (um em 1998, um em 2000, três em 2001, dois em 2006 e três em 2006) e um no Simpósio (um em 2008). Os demais artigos encontrados, apesar de terem mencionado a pesquisa-ação, não a adotaram como estratégia de engajamento metodológico, limitando-se apenas a citá-la no contexto da pesquisa qualitativa como uma de várias estratégias que podem ser usadas ${ }^{\mathrm{i}}$.

Tais evidências indicam em considerável medida o estado atual e a tendência dos estudos nacionais na área de Administração e apontam, pois, para uma utilização ínfima da Pesquisa-Ação na área de Administração do país, - o que diverge do cenário europeu e norteamericano supramencionado. As razões específicas para tal desuso da pesquisa-ação, no Brasil, ainda não foram explicitadas; contudo, a investigação de Coghlan (2004) quanto a possíveis fatores explicativos da não consolidação da Pesquisa-Ação em alguns ambientes acadêmicos pode ser elucidativa nesse sentido. Embasando-se no trabalho de Greenwood (2002), Coghlan (2004) destaca dois principais motivos para a tímida participação da pesquisa-ação em alguns contextos. Primeiramente, o autor aponta para a chamada "supressão", isto é: o fato de que a própria escassez de trabalhos adotando a Pesquisa-Ação reforça a continuidade dessa situação ao limitar indiretamente iniciativas alternativas à tendência metodológica predominante. Em segundo lugar, Coghlan (2004) salienta a negligência em relação ao rigor acadêmico em algumas pesquisas realizadas, dando margem ao frequente questionamento se a Pesquisa-Ação é pesquisa.

Dessa forma, a inércia gerada pela retroalimentação de trabalhos que seguem o mainstream metodológico e a dúvida em relação à legitimidade da Pesquisa-Ação, no que tange à sua contribuição e também ao seu rigor "científico", são as principais causas identificadas por Coghlan (2004) para sua pouca expressão em alguns contextos acadêmicos. 
Diante da constatação feita por Dalmoro et al. (2007) ao analisarem as tendências metodológicas dos artigos publicados nas edições de 1995 a 2006 do EnANPAD, pode-se inferir que, no Brasil, os fatores explicativos para o ínfimo uso da Pesquisa-Ação no campo da Administração não diferem, em essência, desses ressaltados por Coghlan (2004). Afinal, identificou-se que, nessa área do conhecimento, predomina, ainda que com algumas resistências, o paradigma positivista (DALMORO et al., 2007), o qual, de acordo com Coghlan (2004), tende a enfatizar a objetividade, o controle, a escolha racional e a repetibilidade de testes e experimentos como pilares legítimos do conhecimento cientifico. Apesar de esses serem valores epistemológicos importantes, alternativas metodológicas, como a pesquisa-ação, concebidas sob outras perspectivas possivelmente mais aderentes a certos fenômenos têm sua legitimidade questionada pela permanência dos fundamentos positivistas como paradigma predominante. Além disso, o positivismo como paradigma utilizado pelo mainstream também se auto-reforça e relega, portanto, estratégias metodológicas estruturadas sobre outros alicerces epistemológicos à necessidade implícita de adotarem um posicionamento defensivo.

Esse arrazoamento contribui para propor uma potencial explicação para a escassez de trabalhos de Pesquisa-Ação na área de Administração no Brasil. Acreditamos que uma apropriada compreensão e divulgação da natureza da pesquisa-ação e dos pressupostos que a fundamentam poderá contribuir para sustentar uma argumentação a favor da adequação dessa estratégia ao tipo de problema para abordagem pela qual foi concebida, promovendo sua maior inserção no repertório metodológico nacional em Administração. Pressupomos que essa difusão da Pesquisa-Ação poderá fomentar maior engajamento da academia em problemas de relevância social, preenchendo a atual lacuna percebida entre teoria e prática.

As seções que se seguem buscam, respectivamente, caracterizar essa estratégia de pesquisa e contribuir para a legitimidade de seu uso nas ciências administrativas.

\section{A PESQUISA-AÇÃo - EXPLICITANDO SUAS CARACTERÍSTICAS PRINCIPAIS}

De acordo com Thiollent (1996, p. 14):

A Pesquisa-Ação é um tipo de pesquisa social com base empírica que é concebida e realizada em estreita associação com uma ação ou com a resolução de um problema coletivo e no qual os 
pesquisadores e os participantes representativos da situação ou do problema estão envolvidos de modo cooperativo ou participativo.

Eden e Huxmam (1996) citam que Kurt Lewin, foi considerado o pioneiro na introdução da Pesquisa-Ação como estratégia de pesquisa. Lewin na década de 1940 argumentava que a pesquisa em ciências humanas e sociais deveria ser voltada tanto para o estudo de leis gerais, quanto para o diagnóstico de situações particulares, integrando o abstrato e o concreto. Os autores lembram que deriva dessa integração a conhecida frase de Lewin de que não há nada mais prático do que uma boa teoria.

Concebida dessa maneira, acredita-se que essa estratégia apresenta bons resultados em ambientes onde se deseja acoplar pesquisa e ação em um processo no qual os atores, membros representativos da situação investigada, participam junto com os pesquisadores para elucidar, de forma interativa, a realidade na qual estão inseridos, identificando problemas coletivos e buscando e experimentando soluções em situação real (THIOLLENT, 1997). Dessa maneira, a produção e a utilização do conhecimento acontecem de forma simultânea. Nesse sentido, esta estratégia visa aproximar, ao máximo, o pesquisador do objeto pesquisado. Essa proximidade tende a permitir que, por meio de um esforço pontual de pesquisa e da definição de ações concretas de curto e médio prazos, sejam aumentados o conhecimento e a consciência das pessoas envolvidas quanto aos problemas detectados na organização.

Coughlan e Coghlan (2002) entendem que a Pesquisa-Ação é uma pesquisa em ação e não pesquisa sobre uma ação; ou seja, os integrantes da situação investigada além de serem objeto de estudo são, também, participantes da resolução de seus próprios problemas. Rapoport (1970) argumenta que a Pesquisa-Ação tem como objetivo contribuir tanto para as questões práticas dos indivíduos inseridos em uma situação problemática quanto para os objetivos da ciência social. Tem-se, então, produção e uso do conhecimento simultaneamente.

Cabe destacar que, embora o método possibilite a realização de pesquisa e ação concomitantemente, a pesquisa não se restringe a uma forma de ação, pois, além de buscar o equacionamento do problema real, pretende-se aumentar o conhecimento do pesquisador e o conhecimento (ou nível de consciência) dos atores envolvidos. Nesse sentido, Eden e Huxmam (1996) apontam que a estratégia está alinhada ao trabalho de Argyris e Schön (1974), pois aprendizado ocorre em circuito duplo e não apenas em circuito simples, o que pode gerar um praticante reflexivo (ie. reflective practitioner). De fato, na Pesquisa-Ação, a reflexão é a atividade que integra ação e pesquisa (COUGHLAN; COGHLAN, 2002). 
Quadro 1: Proposição de etapas para a Pesquisa-Ação

\begin{tabular}{cll}
\hline Autor & $\begin{array}{c}\text { Proposta de } \\
\text { aplicação }\end{array}$ & \multicolumn{1}{c}{ Descrição } \\
\hline & $\begin{array}{l}\text { Objetiva a compreensão do contexto estudado e da finalidade } \\
\text { da pesquisa. É o momento de conscientização acerca do } \\
\text { projeto e de suas respectivas contribuições, tanto para a } \\
\text { organização quanto para o arcabouço teórico. Não se pode } \\
\text { esquecer nesse momento das forças atuantes no contexto } \\
\text { estudado (políticas, econômicas, técnicas e sociais). }\end{array}$ \\
\hline
\end{tabular}

1. Coleta de dados: uso de técnicas para mapeamento da problemática;

2. Feedback: disposição dos dados para análise. Neste momento, há estreita interação entre pesquisador e membros da organização;

Coughlan

e

Coghlan

(2002)
Ciclo de Seis

Etapas

3. Planejamento da ação: é um conjunto de ações a partir das quais se define onde, quando e como se darão as mudanças desejadas;

4. Implantação: feita pela própria organização, com o apoio de pessoas-chave, é o momento de alocação do projeto de intervenção;

5. Avaliação: reflexão das atividades empreendidas;

6. Construção teórica: momento em que a organização poderá melhorar o processo implantando e o pesquisador irá elaborar sua contribuição teórica.

Deve ocorrer durante todo o ciclo, visando garantir o alcance

Monitoramento dos resultados práticos esperados no "Passo Inicial" e zelar pelo processo de aprendizado dentro da investigação, na perspectiva do pesquisador.

Fase compreensão dos atores envolvidos na trama. O objetivo aqui

Exploratória é detectar, em conjunto com os envolvidos, os diversos

(Diagnóstico) problemas existentes e discutir quais devem ser priorizados dentro do trabalho de investigação e ação coletiva.

\begin{tabular}{cl}
\hline Pesquisa & O foco é conceber instrumentos de pesquisa com base nos \\
Aprofundada & $\begin{array}{l}\text { problemas levantados. Os dados devem ser processados e } \\
\text { organizados (por exemplo, em tabelas e gráficos) para } \\
\text { subsidiar o planejamento da ação. }\end{array}$
\end{tabular}

Thiollent

(1997)

Fase de Ação

1. Definição de objetivos alcançáveis por meio de ações concretas;

2. Apresentação de propostas a serem negociadas entre os atores envolvidos;

3. Difusão dos resultados;

4. Implantação de ações-piloto.

A fase de avaliação é a etapa final da Pesquisa-Ação. Esta possui dois objetivos: (i) controlar a "efetividade" das ações

Fase de

Avaliação no contexto social da pesquisa e suas consequências a curto e médio prazos; e (ii) extrair os conhecimentos ou ensinamentos necessários para estendê-la a outros casos. As três últimas fases da Pesquisa-Ação, na prática, são muito interativas, não apresentando uma sequência rígida de atividades. 
A importância da reflexão fica explícita quando são observadas as propostas de definição - ou planejamento - das etapas a serem seguidas durante o processo de Pesquisa-Ação. Apesar de se considerar que o planejamento está intimamente relacionado às circunstâncias do ambiente no qual está inserida a organização pesquisada (THIOLLENT, 1985), existem, na literatura, algumas propostas gerais de sequência dessas etapas, as quais sempre prevêem a atividade de integração entre ação e pesquisa. O Quadro 1 expõe duas propostas consolidadas no âmbito acadêmico.

Em complementação a essas propostas, Susman e Evered (1978) destacam cinco etapas da Pesquisa-Ação: Diagnóstico, Planejamento da Ação, Execução da Ação, Avaliação e Especificação do Aprendizado. A Figura 1 ilustra esse processo cíclico.

Figura 1: O processo cíclico da pesquisa-ação

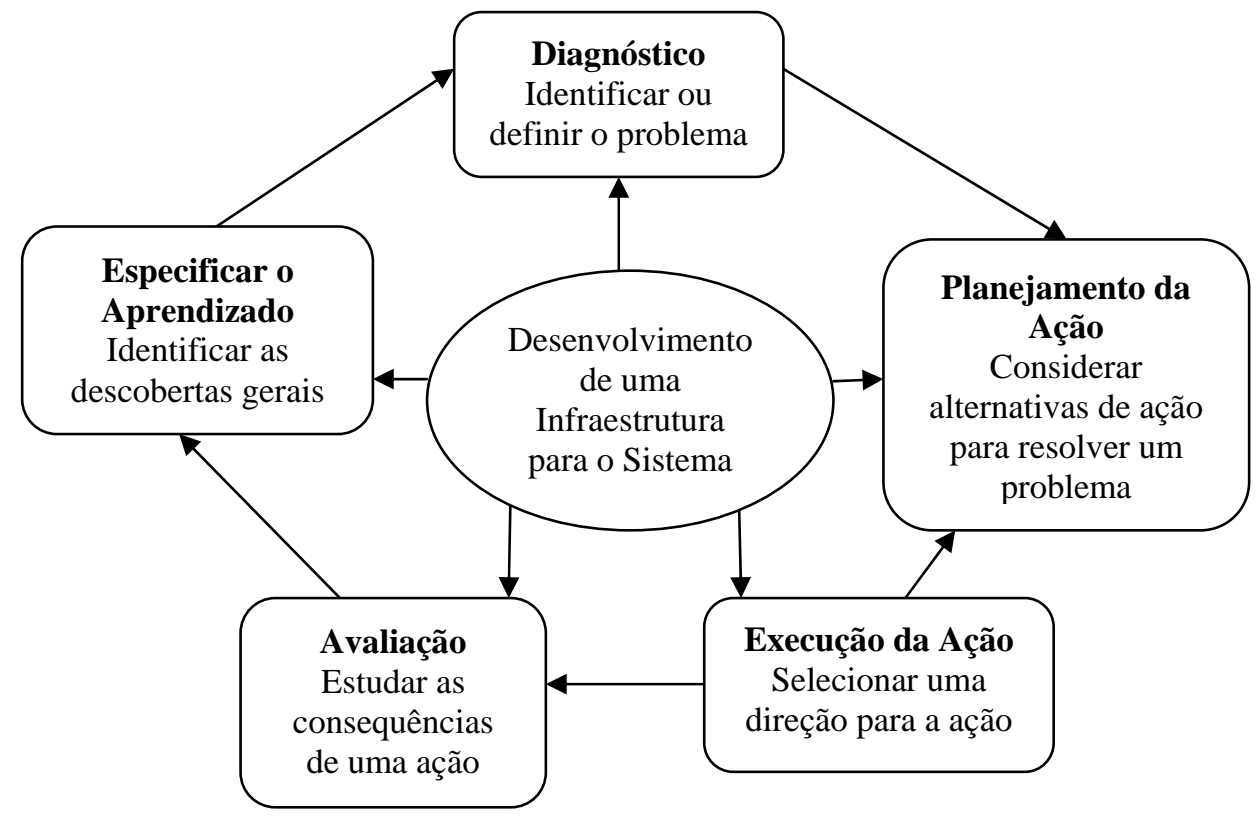

Fonte: Susman e Evered (1978, p. 588).

Em linhas gerais, observa-se que as abordagens sugerem a condução da Pesquisa-Ação em etapas, que podem ser sintetizadas em quatro grandes fases: diagnóstico inicial, planejamento da ação, implantação e análise dos resultados.

Nesse sentido, Schein (1995) distingue entre dois modos principais o auxílio de um pesquisador na mudança de um determinado 
contexto social por meio das fases de diagnóstico, intervenção e monitoramento. O primeiro modo baseia-se no modelo médico-paciente, em que o auxiliador externo é tido como um expert que busca realizar um diagnóstico e prescrever uma ação. O segundo modo, por sua vez, prevê que o pesquisador/auxiliador atuará como facilitador, com o objetivo de ajudar os clientes a definirem melhor seus próprios problemas e conduzirem por si mesmos os processos de elaboração e implantação de soluções. Coughlan e Coghlan (2002) afirmam que, adotando o segundo modo, pesquisadores estariam utilizando efetivamente a Pesquisa-Ação.

Nesse sentido, Riordan (1995) esclarece que a intervenção do pesquisador visará à adequação da descrição da realidade particular do contexto organizacional elaborada pelos clientes da pesquisa. Ao não levar em consideração este traço fundamental, muitos pesquisadores a têm rotulado equivocadamente de consultoria.

Coughlan e Coghlan (2002) chamam a atenção para uma série de diferenças essenciais entre essas duas modalidades de atuação. Entre elas, destaca-se que a Pesquisa-Ação:

a) busca contribuir para os avanços da ciência, enquanto a consultoria se detém na resolução de um problema prático;

b) requer um embasamento teórico para entender a problemática e formular proposições, enquanto a consultoria busca justificar a sua atuação por meio do empirismo;

c) é interativa e cíclica, proporcionando um processo de aprendizado em equipe, enquanto a consultoria é, frequentemente, linear e restrita, limitando o trabalho ao escopo do contrato firmado; e

d) busca capacitar os membros da situação investigada a desenvolverem as mesmas atividades, futuramente, na ausência de participantes externos, enquanto, na consultoria, o conhecimento permanece com o consultor.

De fato, o não entendimento dos pressupostos subjacentes à prática da Pesquisa-Ação tem feito com que o termo referente a esta estratégia seja frequentemente mal empregado, sendo utilizado indiscriminadamente como referência a abordagens consideravelmente distintas. Dash (1999) identifica este como um dos problemas que caracterizavam os principais debates acerca da pesquisa-ação na virada do século. Revisando várias formas e alguns principais representantes desta abordagem em diversos campos do conhecimento, o autor localiza a emergência da citada estratégia metodológica e de suas problemáticas apoiando-se numa perspectiva multifacetada. Neste percurso, soluções até então propostas são discutidas e questões a serem debatidas são apresentadas. 
Na linha de debates em torno da Pesquisa-Ação, aponta-se, por exemplo, que vários relatos de consultoria utilizam o termo apenas para conferir status de aparente rigor cientifico ao trabalho realizado (EDEN; HUXHAM, 1996). Grande parte do mau uso da Pesquisa-Ação é atribuído à predominante incompreensão, por parte dos praticantes, dos fundamentos metodológicos que embasam a Pesquisa-Ação e a distinguem de outras estratégias de pesquisa, o que faz com que seja necessário não restringir a discussão às características e fases principais desta estratégia e exigir uma abordagem mais explícita de seu embasamento teórico - conforme se propõe na próxima seção.

\section{EM DEFESA DA PESQUiSA-AÇÃo - EsClARECENDO SEUS FUNDAMENTOS PARA RECUPERAR SUA LEGITIMIDADE}

A despeito da polissemia adquirida pela expressão pesquisa-ação, há concordância em que sua especificidade reside na propriedade de que os resultados das pesquisas realizadas com esta estratégia advêm de um envolvimento do pesquisador com membros de uma organização, em torno de uma questão que tenha importância efetiva para estes (EDEN; HUXHAM, 1996).

Dessa forma, os projetos de Pesquisa-Ação devem ser compreendidos como estudos de situações específicas que, em geral, não contribuem diretamente (apesar de o fazerem indiretamente) para a criação de conhecimento universal. A investigação tende a ser localizada, aplicada a casos particulares e em busca do diagnóstico e da tomada de decisões em contextos organizacionais. Nesse sentido, cada intervenção é, em certa medida, particular ao ambiente organizacional estudado, fato que tem gerado inúmeras críticas à estratégia, no sentido de falta de repetibilidade e, consequentemente, falta de rigor científico. Apesar disso, defende-se que o acúmulo de um número considerável de intervenções em casos semelhantes pode e deve contribuir para a evolução da teoria até conclusões e casos mais gerais (EDEN; HUXHAM, 1996).

Visando à defesa da Pesquisa-Ação, argumenta-se que ela, assim como qualquer abordagem científica tradicional, (i) também insiste na produção de dados válidos e confiáveis; (ii) também requer que sejam explícitas as inferências baseadas nos dados e na teoria; (iii) também exige que os argumentos sejam passíveis de avaliação intersubjetiva (o que corresponderia ao teste público de hipóteses na ciência tradicional); e (iv) também tem a ambição de gerar teoria sistemática. Entretanto, em 
contraposição à perspectiva científica ortodoxa, sugere-se que uma estratégia de tipo clínica, e não laboratorial, é mais adequada à natureza dos objetos estudados, a saber: sistemas sociais humanos em processo (RIORDAN, 1995). Afinal, para aquelas pesquisas nas quais a dimensão humana e social do fenômeno sob investigação se faz presente, os pressupostos subjacentes à estratégia escolhida devem ser diferentes dos aplicados na tradicional abordagem positivista, que, segundo Thiollent (1996, p. 7): ''demonstram grande preocupação com a quantificação de resultados empíricos, em detrimento da busca de compreensão e de interação entre pesquisadores e membros das situações investigadas"'.

Nesse sentido, em conformidade com Susman e Evered (1978), os pressupostos positivistas não seriam plenamente adequados para gerar conhecimento a respeito de situações particulares das organizações e, em especial, para desenvolver métodos que permitissem abordar os problemas existentes na mesma, já que:

- As organizações são artefatos criados pelos homens para atender seus objetivos;

- As organizações são sistemas de ações humanas nos quais os meios e os fins são regidos por valores;

- As observações empíricas e as reconstruções lógicas das atividades organizacionais não são suficientes para a ciência das organizações, visto que estas são planejadas de acordo com a visão de futuro de seus integrantes e podem ser entendidas experimentalmente pelos pesquisadores organizacionais sem a necessidade de fundamentação empírica ou validação lógica;

- As organizações são únicas, não devendo haver grande preocupação de generalização dos resultados de suas análises para outros casos.

O posicionamento antipositivista, portanto, argumenta que o mundo social é essencialmente relativista e só pode ser entendido pelo ponto de vista dos indivíduos diretamente envolvidos nas atividades estudadas (BURRELL; MORGAN, 1979). A Pesquisa-Ação, nesse sentido, está de um modo geral, alinhada a esse pensamento. Por isso, em se tratando de pesquisa organizacional, a epistemologia antipositivista em especial a Pesquisa-Ação - intenta superar algumas das limitações da concepção tradicional de pesquisa, na qual são valorizados critérios lógicos, formais e estatísticos. As diferenças entre ciência positivista e Pesquisa-Ação encontram-se sumarizadas no Quadro 2.

Avaliando estes fundamentos filosóficos da pesquisa-ação, Riordan (1995) argumenta que a Ciência-Ação (como é por ele chamada) é uma valiosa contribuição para a filosofia das ciências sociais, uma vez 
que combina o pólo exploratório e o interpretativo de uma maneira satisfatoriamente coerente. Dessa forma, os objetivos de explicação e de compreensão são integrados nesta estratégia, conjugando, no plano epistemológico, tanto elementos da abordagem empiricista quanto da hermenêutica. A Pesquisa-Ação tanto incorpora a busca por entendimento dos significados como mantém a preocupação com a confiabilidade da pesquisa, prevenindo-se da adoção acrítica dos pontos de vista internos dos participantes da investigação (RIORDAN, 1995).

Quadro 2: Comparação entre a ciência positivista e a Pesquisa-Ação

\begin{tabular}{|c|c|c|}
\hline $\begin{array}{c}\text { Pontos de } \\
\text { comparação }\end{array}$ & Ciência positivista & Pesquisa-Ação \\
\hline Objetivo de pesquisa & $\begin{array}{l}\text { Conhecimento universal: } \\
\text { construção e teste de teorias }\end{array}$ & $\begin{array}{c}\text { Conhecimento em ação: } \\
\text { construção e teste de teorias em } \\
\text { ação } \\
\end{array}$ \\
\hline $\begin{array}{l}\text { Base para assumir a } \\
\text { existência das } \\
\text { unidades } \\
\end{array}$ & $\begin{array}{l}\text { Existem independentemente } \\
\text { dos seres humanos }\end{array}$ & $\begin{array}{l}\text { São artefatos humanos para } \\
\text { propósitos também humanos }\end{array}$ \\
\hline $\begin{array}{l}\text { Papel das unidades } \\
\text { estudadas }\end{array}$ & $\begin{array}{l}\text { Os membros do sistema- } \\
\text { cliente são objetos de estudo }\end{array}$ & $\begin{array}{l}\text { Os membros do sistema-cliente } \\
\text { são sujeitos autorreflexivos com } \\
\text { os quais existe colaboração }\end{array}$ \\
\hline Papel do pesquisador & Observador & Ator, agente de mudança \\
\hline $\begin{array}{l}\text { Relação do } \\
\text { pesquisador com o } \\
\text { ambiente } \\
\end{array}$ & Neutra ou separada & Imersa no ambiente \\
\hline $\begin{array}{c}\text { Linguagem para } \\
\text { descrever as unidades }\end{array}$ & Denotativa, observacional & Conotativa, metafórica \\
\hline Perspectiva de tempo & Observação do presente & $\begin{array}{c}\text { Observação e interpretação do } \\
\text { presente, com base no } \\
\text { conhecimento do passado; } \\
\text { concepção de um futuro mais } \\
\text { desejável } \\
\end{array}$ \\
\hline Posição de valor & Métodos são neutros & $\begin{array}{c}\text { Desenvolvem os sistemas sociais } \\
\text { e revelam o potencial humano }\end{array}$ \\
\hline $\begin{array}{l}\text { Natureza da validação } \\
\text { dos dados }\end{array}$ & $\begin{array}{l}\text { Independente do contexto, } \\
\text { lógica, mensurável e } \\
\text { consistente com } \\
\text { prognósticos e controles }\end{array}$ & Depende do contexto, empírica \\
\hline $\begin{array}{l}\text { Bases para } \\
\text { generalização }\end{array}$ & $\begin{array}{l}\text { Ampla, universal e livre de } \\
\text { contexto }\end{array}$ & $\begin{array}{l}\text { Estreita, situacional e limitada } \\
\text { pelo contexto }\end{array}$ \\
\hline
\end{tabular}

Fonte: Adaptado de Susman e Evered (1978) e Coughlan e Coghlan (2002).

De acordo com Riordan (1995), o embasamento da Pesquisa-Ação na Ciência-Ação promovida por Argyris e Schön (1974), no praticante reflexivo e na ideia de cultura organizacional apresentada por Schein 
(1995), faz desta estratégia uma abordagem para o estudo da realidade social que não separa (apesar de distinguir) valor de fato; afinal, ela requer um praticante da ciência que não somente engaja-se ativamente como um participante na organização, mas também que incorpora a perspectiva do observador crítico e analítico. Dessa forma, advoga-se que o uso da Pesquisa-Ação pode contribuir para que a avaliação dos valores e dos comprometimentos políticos nas organizações seja tão crítica quanto o usual julgamento acerca dos juízos de fato vigentes (RIORDAN, 1995).

Thiollent (1985) afirma que o potencial de contribuição da estratégia ocorre porque a Pesquisa-Ação, diferentemente das abordagens positivistas, reconhece que as situações sociais vêm sempre acompanhadas de um nítido componente normativo e, como tal, não pode ser desprezada pelo pesquisador. Este deve incluir em seu recorte de pesquisa tanto a dimensão ideológica quanto as relações de poder nas quais a organização está imersa. Nesse sentido, o autor ressalta que:

\begin{abstract}
É preciso salientar que o componente normativo não é necessariamente homogêneo; suas variações e sua diversidade são o próprio reflexo das crises da ideologia dominante e das situações de conflito que ocorrem na sociedade. Muitas das normas sociais que contêm as doutrinas organizacionais têm a ver com estratégias e táticas do poder, tendo em vista a manutenção de certa forma de 'consenso', de 'integração social' ou de melhor 'participação' ou 'cooperação' das partes dirigidas, o que seria suscetível de aumentar a produtividade e reduzir a intensidade dos conflitos (THIOLLENT, 1985, p.64).
\end{abstract}

Nota-se que, de maneira distintiva, a Pesquisa-Ação existe no contexto organizacional valorativamente atrelada a uma política de transformação do status quo, buscando facilitar a mudança dos comportamentos e estabelecer um diálogo que favoreça a participação dos trabalhadores e dos executivos na resolução conjunta dos problemas organizacionais (THIOLLENT, 1985).

Nesse sentido, Putnam (1999) percebe a Pesquisa-Ação em consonância com a Teoria Crítica - tal qual concebida por Habermas (1971) - uma vez que a Pesquisa-Ação está engajada na busca por interesses emancipatórios, aprofundando-se nos dilemas vivenciados, estimulando a busca por alternativas e levando os indivíduos a uma reflexão crítica de suas próprias condutas e práticas culturais. Dessa forma, a utilização dessa estratégia metodológica demandaria, por parte do pesquisador, a habilidade de delinear, identificar e indagar acerca das inconsistências nas ações dos atores envolvidos para que os participantes 
possam dar continuidade ao processo de reflexão e aprendizagem. Essa forma de intervenção geraria momentos no qual os indivíduos poderiam reconsiderar seus pressupostos sedimentados. Tais momentos poderiam levar os envolvidos a desenvolver um senso de responsabilidade pessoal com a mudança, com potencial para viabilizar transformações pessoais (PUTNAM, 1999).

É nesse sentido que Coghlan (2002) enfatiza e analisa a noção de nível de análise como foco da pesquisa-ação. Utilizado como uma estrutura de apreensão dos aspectos organizacionais, esse construto propicia a concepção da organização como uma hierarquia de sistemas organizados em diferentes graus de complexidade. Dessa forma, essa noção torna-se de destacada relevância para a Pesquisa-Ação, na medida em que permite recortar o fluxo da vida real sob investigação em termos de situações problemáticas e analisar a dinâmica do desdobramento das intervenções em relação a outros níveis de análise, que não o enfocado. Assim, um projeto de pesquisa-ação envolve, em princípio, desde os indivíduos diretamente participantes no processo até a própria organização e seu ambiente, passando pelos grupos e relações intergrupais. Nesse sentido, o pesquisador, ao se tornar um participante da resolução do problema, percebe-se inserido nessa dinâmica de múltiplos níveis, devendo considerá-la explicitamente para que a intervenção gerada seja, de fato, sistêmica.

Thiollent (1985) ressalta que a Pesquisa-Ação, ao buscar se aproveitar dos fenômenos de tomada de consciência, dos fluxos de afetividade e do potencial de criatividade contidos nas organizações, assume uma postura que rompe com o ideal de não interferência no fenômeno estudado, adotando uma concepção metodológica oposta. Isso significa a interferência explícita no objeto investigado, fazendo com que este passe a colaborar na própria investigação associada à ação.

É nesse sentido que Styre e Sundgren (2005) argumentam a favor da aplicabilidade das metáforas da experimentação e do laboratório para posicionamento da pesquisa-ação em relação a outras estratégias de pesquisa, no campo dos estudos organizacionais. Afinal, para esses autores, um pesquisador, adotando a Pesquisa-Ação, realizará a pesquisa in vivo, enfrentando problemas reais em contextos organizacionais específicos ao contrário de estabelecer um ambiente controlado em que algumas variáveis poderiam ser isoladas. Contudo, assim como nas ciências de laboratório, quando esse pesquisador intervém na situação, essa intervenção tem sempre um caráter experimental, configurando-se como passos iniciais de uma estratégia emergente e não como ações 
deliberadas visando ao alcance de objetivos claramente estabelecidos $a$ priori. Utilizando-se de um estudo em uma grande multinacional farmacêutica, Styre e Sundgren (2005) concluem que o pesquisador orientado pela Pesquisa-Ação é guiado pela dúvida e pelo desejo de reflexão, visando tanto entender as atividades organizacionais quanto melhorá-las com base em uma pesquisa intervencionista e experimental.

Entretanto, para que essa interferência, relevante para a resolução de problemas reais, não se torne sinônimo de falta de rigor acadêmico, Eden e Huxham (1996) identificam e avaliam alguns dos principais determinantes das características da Pesquisa-Ação. Os autores visam explicitar o que definiria a qualidade de uma pesquisa que adotasse esta estratégia de pesquisa no contexto de investigações em organizações. Nesse sentido, procura-se mostrar como esta estratégia de investigação pode, observando-se certos princípios, conjugar satisfatoriamente rigor e relevância. Como proposta, estes autores apresentam doze diretrizes para a utilização da Pesquisa-Ação no contexto das ciências administrativas, sendo seis voltadas para os resultados da investigação e seis para o próprio processo de pesquisa. A intenção dos autores não é fornecer uma receita para o sucesso nem defender o número de diretrizes propostas, mas apenas propor um sumário com base no arcabouço correlato de alguns princípios (relacionados à estratégia) cuja observação pode ser particularmente importante para os pesquisadores da área de Administração. As seis diretrizes relativas aos resultados da PesquisaAção estão sintetizadas abaixo.

1. A Pesquisa-Ação tem que ter implicações que vão além daquelas requeridas para a ação ou a geração de conhecimento no contexto do projeto (dessa forma, evitam-se tanto o extremo do contextualismo exacerbado quanto o do generalismo histórico);

2. Apesar de ser voltada para a aplicação em situações reais cotidianas, a Pesquisa-Ação demanda uma preocupação explícita com a teoria subjacente à prática;

3. A generalidade da Pesquisa-Ação não é obtida pelo projeto de métodos, técnicas e ferramentas padronizadas, mas pode ser construída a partir de teorias consistentes como forma de dar embasamento ao instrumental pragmático;

4. A Pesquisa-Ação gerará teoria emergente, isto é, teorias que são uma síntese entre os dados gerados e as teorias que foram utilizadas como arcabouço teórico para o diagnóstico e intervenção;

5. A construção de teoria, resultante de projetos de Pesquisa-Ação, será incremental, indo do particular para o geral, gradativa e lentamente; 
6. O pesquisador que utilizar a Pesquisa-Ação deve abandonar a dicotomia descrição-prescrição, reconhecendo que a descrição, ao representar determinados elementos da situação e não outros, também é, ainda que implicitamente, uma prescrição. Coughlan e Coghlan (2002) reforçam que, na Pesquisa-Ação, pela grande proximidade do pesquisador em relação ao seu objeto de pesquisa, o próprio pesquisador deve estar ciente de que ele mesmo atuará como um instrumento na geração de dados. É nesse sentido que Riordan (1995) afirma que a observação pretensamente imparcial é, em si, uma intervenção.

As outras seis diretrizes, voltadas para o processo da PesquisaAção, são:

7. Uma reflexão altamente metódica e ordenada deve ser mantida para a interpretação dos dados emergentes a cada estágio da intervenção;

8. O processo de exploração dos dados deve ser, do ponto de vista intersubjetivo, rastreável, sendo justificado por meio de argumentação e/ou análise;

9. A adesão aos oito princípios supracitados deve ser reconhecida como condição necessária, mas não suficiente para a validade da PesquisaAção;

10. A utilização da estratégia deve poder ser justificada pela impossibilidade de alternativas metodológicas coletarem e explorarem a riqueza de dados permitida pela Pesquisa-Ação;

11. A triangulação deve ser utilizada na Pesquisa-Ação como exercício dialético que favoreça o enriquecimento da crítica sobre os resultados preliminares obtidos; e

12. A história e o contexto da intervenção devem ser tomados como aspectos críticos na interpretação da validade e da aplicabilidade dos resultados da pesquisa.

Mais recentemente, de maneira semelhante, mas mais sucinta, Bargal (2008) extraiu e desenvolveu oito princípios fundamentais da pesquisa-ação baseados nos escritos de Kurt Lewin, ilustrando-os por meio de um estudo de campo voltado para a redução de conflito intergrupal em escolas superiores. Os oito princípios foram sistematizados da forma que segue. A Pesquisa-Ação:

1. Combina um estudo sistemático, por vezes experimental, de um problema social bem como as iniciativas para solucioná-lo;

2. Inclui um processo espiral de coleta de dados para determinar metas, ações para implantar metas e avaliação dos resultados da intervenção;

3. Requer retroalimentação dos resultados da intervenção para todas as partes envolvidas na pesquisa; 
4. Implica cooperação contínua entre pesquisadores e praticantes;

5. Baseia-se nos princípios de dinâmica de grupo e está ancorada em suas fases de mudança. As fases são descongelamento, movimento e recongelamento. A tomada de decisão é mútua e é conduzida de uma maneira pública;

6. Leva em consideração questões de valor, objetivos e necessidades de poder das partes envolvidas;

7. Serve para criar conhecimento, formular princípios de intervenção e desenvolver instrumentos para seleção, intervenção e treinamento; e

8. No seu âmbito da estrutura do trabalho, há uma ênfase no recrutamento, treinamento e suporte dos agentes de mudança.

Nesta formulação, a Pesquisa-Ação é entendida como uma estratégia de pesquisa que lida com a criação de mudança em sistemas humanos. Nesse sentido, envolve tanto pesquisa quanto intervenção, tanto reflexão em ação quanto sobre a ação, tanto estudo quanto construção da situação.

Checkland e Holwell (1998), em complementação a esses estudos de compilação de princípios a serem observados para que uma pesquisa se caracterize como pesquisa-ação, argumentam que a validade da PesquisaAção depende da possibilidade de rastreabilidade intersubjetiva do processo de pesquisa, possibilitada pela explicitação, preliminar à pesquisa, da epistemologia em termos da qual os achados que contarão como conhecimento serão expressos. $\mathrm{O}$ argumento se baseia na observação de que, sendo o método incapaz de atender aos requisitos da replicação, que caracterizam as ciências naturais, pesquisadores investigando fenômenos sociais por meio da Pesquisa-Ação devem agir de forma a alcançar uma situação, na qual o processo de pesquisa seja recuperável, no sentido popperiano, por terceiros interessados na investigação realizada, fomentando a crítica intersubjetiva (CHECKLAND; HOLWELL, 1998).

Para que isso ocorra é essencial a afirmação a priori da epistemologia (entendida como o conjunto de ideias e o processo pelo qual elas serão usadas metodologicamente), por meio da qual o pesquisador fará sentido do processo e dos resultados de sua pesquisa. O posicionamento epistemológico preliminar, segundo os autores em questão, é que dará à Pesquisa-Ação uma legitimidade consistente, pois, dessa forma, apesar de não poder se basear em experimentação laboratorial, também não se desencaminhará para atender meramente ao insuficiente critério de plausibilidade. Portanto, em conclusão, argumentase que o grau de recuperabilidade das razões que levaram a pesquisa ao 
rumo tomado, tendo-se em vista o framework teórico previamente declarado pelos facilitadores, é um dos critérios mais apropriados para se julgar um trabalho configurado como Pesquisa-Ação (CHECKLAND; HOLWELL, 1998).

Tomando por ponto de partida o trabalho de Checkland e Holwell (1998), Champion e Stowell (2003) aprofundam o tratamento da problemática da validação de estudos de campo orientados com o método de pesquisa-ação. Estes autores reconhecem na noção de recuperabilidade um avanço significativo na abordagem das dificuldades relacionadas ao estabelecimento do rigor e da validade da Pesquisa-Ação. Contudo, visam não só recuperar o caminho seguido durante a investigação, mas também a maneira como esta foi realizada, a fim de tornar possível uma percepção pública da autenticidade e credibilidade da investigação emergente.

Tendo esse objetivo, os autores propõem um instrumento intelectual multidimensional para validação, de maneira mais abrangente, de estudos de Pesquisa-Ação. As dimensões propostas e as respectivas questões correlatas são as seguintes:

- Participantes, incluindo a escolha dos envolvidos, o critério para inclusão, razões para não participação, ou exclusão;

- Engajamento: incluindo métodos e ferramentas empregadas para engajar as pessoas no processo de aprendizagem;

- Autoridade: incluindo reflexão sobre quem autorizou ou apoiou quais elementos da investigação com quais propósitos;

- Relacionamentos: incluindo análise de relações em desenvolvimento ou planejadas entre indivíduos e entre a situação enfocada e seu ambiente;

- Aprendizagem: registro de intervenções (ou não intervenções) acordadas, do progresso dos participantes rumo à decisão e dos aprendizados gerados pela realização da ação.

Atentando o pesquisador para a publicação da maneira como esses aspectos foram abordados durante a investigação, Champion e Stowell (1998) consideram que indivíduos que não participaram do processo teriam as condições de julgar e reconhecer, publicamente, a autenticidade ou não do trabalho, estabelecendo os méritos da pesquisa.

\section{APRECIAÇÃo CrítiCA E CONSIDERAÇões FiNAIS}

Neste trabalho, diante da constatação do uso consideravelmente restrito da Pesquisa-Ação no Brasil na área de Administração, buscou-se, em defesa desta estratégia de pesquisa, fundamentar argumentos para corroborar sua 
legitimidade. Para isso, foram sintetizados os traços típicos da PesquisaAção, bem como suas etapas principais e os pressupostos teóricos que a fundamentam. Salientou-se, como distinção central desta estratégia metodológica para as demais, o fato de que a Pesquisa-Ação é usualmente adotada quando a problemática pesquisada mostra-se complexa e pouco explorada, demandando uma forte interação dos pesquisadores com o objeto de pesquisa, partindo-se de questões que sejam prioritariamente relevantes para os próprios sujeitos imersos na situação sob estudo (RAPOPORT, 1970; SUSMAN; EVERED, 1978; COUGHLAN; COGHLAN, 2002). Nessas circunstâncias, a Pesquisa-Ação, com sua característica não positivista, visando à resolução e/ou elucidação de um problema real particular apoiado na intervenção colaborativa com os atores da organização, torna-se uma estratégia de engajamento consideravelmente relevante para as ciências organizacionais, em geral, e para as administrativas, em particular.

Nesse sentido, explicitou-se que, uma vez adotada esta estratégia, durante todo o período de pesquisa, deve haver, necessariamente, um processo cíclico e iterativo de diagnóstico do problema, planejamento da ação, intervenção, avaliação dos resultados e consolidação do aprendizado. Esse processo usa, basicamente, instrumentos de coleta, análise e síntese de informação. Por fim, ressaltou-se a necessidade de aliar a essa prática uma profunda compreensão dos pressupostos que a fundamentam, a fim de que o resultado da pesquisa contribua não somente para a solução do problema organizacional, mas, principalmente, para refinar o arcabouço teórico correlato, baseado na reflexão crítica sobre a ação.

\section{REFERÊNCIAS}

ARGYRIS, C.; SCHÖN, D, A. Theories in Practice. San Francisco: Jossey-Bass, 1974.

BARGAL, D. Action Research: a paradigm for achieving social change. Small Group Research, v. 39, n.1, p. 17-27, 2008.

BURRELL, G.; MORGAN, G. Sociological paradigms and organisational analysis. London: Heineman, 1979.

CHAMPION, D.; STOWELL, F.A. Validating action research field studies: PEArL. Systemic Practice and Action Research, v. 16, n.1, p. 2136, 2003. 
CHECKLAND, P.B.; HOLWELL, S. Action Research: its nature and validity. Systems Practice and Action Research, v. 11, n.1, p. 9-21, 1998.

COGHLAN, D. Interlevel dynamics in systemic action research. Systemic Practice and Action Research, v. 15, n. 4, p. 273-283, 2002.

COGHLAN, D. Action Research in the Academy: Why and Whiter? Reflections on the Changing Nature of Research. The Irish Journal of Management, v. 25, n 2, p.1-11, 2004.

COUGHLAN, P.; COGHLAN, D. Action research for operations management. International Journal of Operations and Production Management, v. 22, n. 2, p. 220-240, 2002.

DALMORO, M.; CORSO, K.B.; FALLER, L.P.; WITTMANN, M.L. Dominância Epistemológica em Estudos do Campo: São Ainda os Administradores Positivistas? In: ENCONTRO NACIONAL DOS PROGRAMAS DE PÓS-GRADUAÇÃO EM ADMINISTRAÇÃO EnANPAD-RJ, 31., 2007, Rio de Janeiro. Anais... Rio de Janeiro: Anpad, 2007.

DASH, D.P. Current debates in action research. Systemic Practice and Action Research, v. 12, n. 5, p. 457-492, 1999.

EDEN, C.; HUXHAM, C. Action Research for management research. British Journal of Management, v.7, n.1, p. 75-86, 1996.

GREENWOOD, D. Action Research: Unfulfilled Promises and Unmet Challenges. Concepts and Transformation, v. 7, n.2, p.117-40, 2002.

HABERMAS, J. Knowledge and Human Interests. Boston: Beacon Press, 1971.

PUTNAM, R.W. Transforming social practice: an action science perspective. Management Learning, v.30, n.2, p. 177-187, 1999.

RAPOPORT, R. Three dilemmas of action research. Human Relations, v.23, n.1, p.459-513, 1970.

RIORDAN, R. The philosophy of action science. Journal of Managerial Psychology, v. 10, n.6, p.6-13, 1995.

SCHEIN, E. Process consultation, action research and clinical inquiry, are they the same? Journal of Managerial Psychology, v. 10, n.6, p. 14-19, 1995. 
STYRE, A.; SUNDGREN, M. Action research as experimentation. Systemic Practice and Action Research, v. 18, n.1, p. 53-65, 2005.

SUSMAN, G.; EVERED, R. An assessment of the scientific merits of action research. Administrative Science Quarterly, v.23, n.1, p.15-25, 1978.

THIOLLENT, M. Crítica metodológica, investigação social e enquête operária. São Paulo: Polis, 1985.

THIOLLENT, M Metodologia da Pesquisa-Ação. São Paulo: Cortez, 1996.

THIOLLENT, M. Pesquisa-Ação nas Organizações. São Paulo: Atlas, 1997. 
DAdos dos Autores

JONATHAN FREITAS (jonathanbra@gmail.com)

Mestre em Administração pela UFMG

Instituição de vinculação: Doutorando em Administração na Universidade

Federal de Minas Gerais

Belo Horizonte/MG - Brasil

Áreas de interesse em pesquisa: Administração Estratégica e Gestão da Inovação Tecnológica.

Daniel Calbino (dcalbino@yahoo.com.br)

Mestre em Administração pela UFMG

Instituição de vinculação: Doutorando em Administração na Universidade

Federal de Minas Gerais

Belo Horizonte/MG - Brasil

Áreas de interesse em pesquisa: Economia Solidária, Teoria Crítica e Pedagogia Crítica.

AleXandre SANTos (mralexandresantos@gmail.com)

Instituição de vinculação: Doutorando em Administração na Universidade Federal de Minas Gerais

Belo Horizonte/MG - Brasil

Áreas de interesse em pesquisa: Governança, Relações de Poder e Simbolismo.

RAFAel Diogo Pereira (rafaelbhtour@yahoo.com.br)

Mestre em Administração pela UFMG

Instituição de vinculação: Doutorando em Administração na Universidade Federal de Minas Gerais

Belo Horizonte/MG - Brasil

Áreas de interesse em pesquisa: Governança Corporativa, Organizações Familiares e Gestão de Empreendimentos Turísticos.

Recebido em: 23/10/2009 • Aprovado em: 30/08/2010

\footnotetext{
${ }^{\mathrm{i}}$ A principal limitação desse levantamento é a restrição da busca realizada aos resumos dos trabalhos, uma vez que o sistema de consulta disponível no site da ANPAD limita a pesquisa a esse campo do artigo. Assim, trabalhos que utilizaram a pesquisa-ação, mas que não fizeram uso dessa expressão no resumo não foram encontrados. De qualquer maneira, considera-se que o levantamento realizado, ao abranger diversos eventos de abrangência nacional, permite um bom indicador preliminar do uso da PA nas pesquisas da área de Administração.
} 